traduções]

\title{
Joias Bijoux Sthéphane Mallarmé
}

Tradução de: MALLARMÉ, S. La dernière mode: gazette du monde e de la famille. Paris: Editions Ramsey, 1874. 


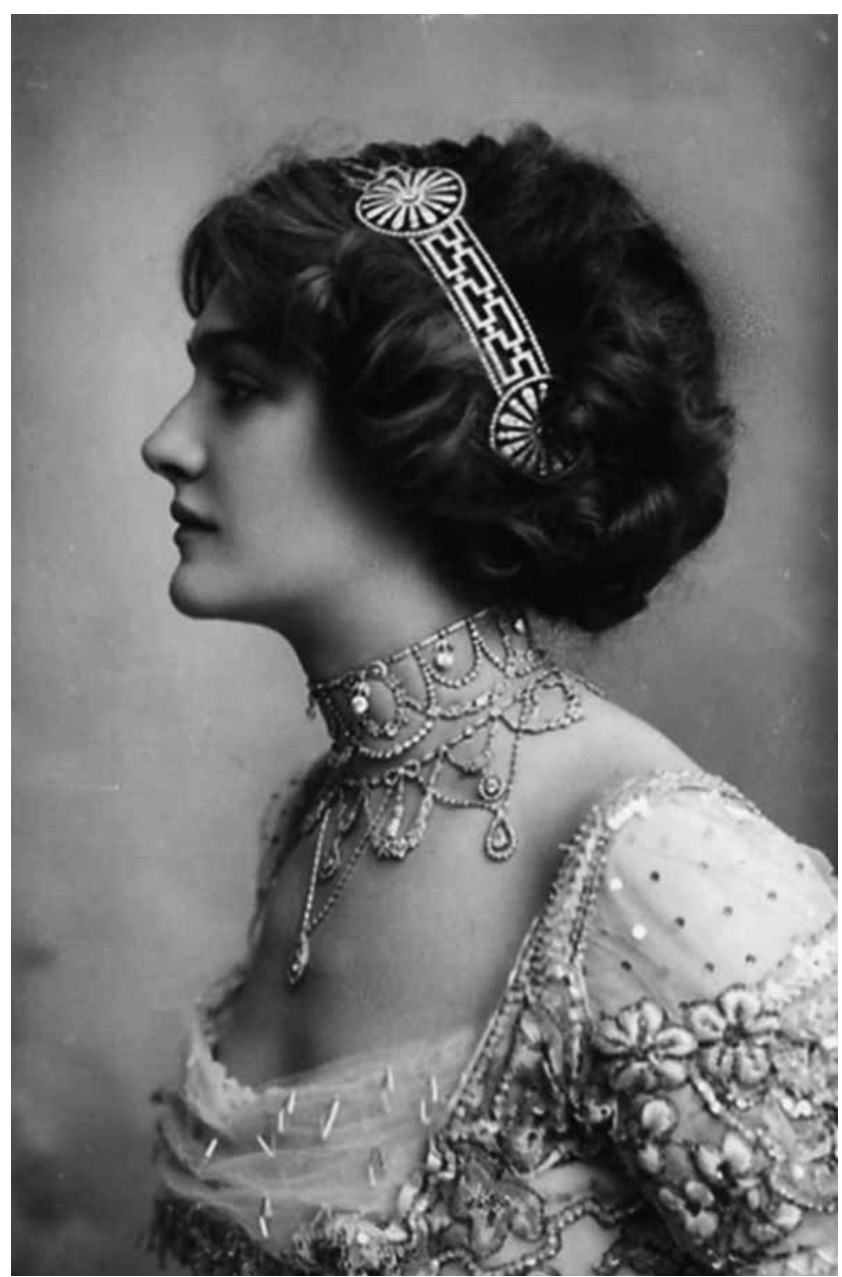

Figura 1 - Imagem da atriz inglesa Lily Elsie, adornada com o esplendor das joias que compunham seu figurino na opereta de teatro A viúva alegre (1905).

Fonte: Pinterest.

Tarde demais para falar da moda de verão e cedo demais para falar da de inverno (ou mesmo da de outono): apesar de algumas grandes confecções de Paris já se ocuparem, como sabemos, de suas coleções para o fim do outono. Hoje, mesmo não tendo à mão os elementos necessários para começar a se vestir, queremos entreter nossas leitoras com objetos úteis para quando terminarem de se aprontar: as Joias. Paradoxo? Não: não haveria nas joias alguma coisa de permanente, e da qual convém falar em uma revista de moda, destinada a comentar a moda de julho a setembro?

Procuremos a joia isolada em si mesma. Onde? Por toda parte: quer dizer, um pouco sobre a superfície do globo e muito em Paris, pois Paris supre o mundo de joias. 0 quê! Todo lugar, por sua natureza, como uma flora, não apresenta, feito pelas mãos de um homem, um porta-joias completo? 0 instinto de beleza e de relação com os diversos climas, que regula, sob cada céu, a produção das rosas, das tulipas e dos cravos é diferente daquela dos brincos, dos anéis, das pulseiras? Flores e joias: cada espécie, como diriamos, não teria o seu próprio solo? Tal brilho do sol convém a essa flor, tal tipo de mulher a essa joia. Essa harmonia natural reinou no passado, mas parece ter sido abolida no presente; à exceção dos povos, que aos olhos de todos permaneceram bárbaros, ou ainda certos camponeses, que em nosso país são considerados rebeldes à civilização. A Civilização! Leiam: "A época em que desapareceu quase todo o poder criativo, tanto na joalheria como no mobiliário"; e tanto em um como no outro, somos forçados a ressuscitar ou 
importar. Importar o quê? As pulseiras de vidro filetado da Índia e os brincos de papel recortado da China? Não, mas, frequentemente, o gosto simples que esteve presente em sua confecção. Ressuscitar o quê? Os pesados ornamentos dos séculos esquecidos, feitos para realçar, com um brilho violento, os veludos do teatro e os brocados de sacristia? Não, mas a audácia com a qual eles são colocados como toques magistrais sobre as vestimentas. Quem sabe? É preciso que cheguemos até mesmo ao ponto de junção anterior dessas duas inspirações, muito diferentes, da arte do ourives: isto é, à Antiguidade clássica e bárbara. Nosso Museu Campana (nos lembramos dele): perguntem aos grandes joalheiros, quer eles se chamem Froment-Meurice, Rouvenat ou Fontenay, se sua admirável ciência, inteiramente crítica, não provém daí, assim como as vitrinas do Hôtel de Cluny ou o Balcão parisiense dos vendedores japoneses ou mesmo argelinos.

Assim, somente Paris é capaz de encontrar prazer em resumir o universo, ela mesma, museu tanto quanto bazar: não há nada que ela não aceite, estranho; não há nada que ela não venda; delicioso. Londres, de fato, tem joias, singulares, maciças, e eu vejo aí um certo charme intimo, preferivel somente a um de nossos defeitos, a saber, no ramo da joalheria, o de sermos brilhantes, permaneçamos simplesmente, aqui, decorativos. A Decoração! Tudo está nessa palavra; e eu aconselharia a uma senhora, que está indecisa quanto a quem confiar o desenho de uma joia desejada, a pedir este desenho ao arquiteto que construiu sua casa, em vez de pedir à costureira ilustre que traz seu vestido de gala. Tal é, em uma palavra, a arte da joia; e isso dito, para jamais voltar a esse ponto, passemos de alguns lugares-comuns a alguns detalhes.

Nada mais simples: hoje, está provado que um passeio de várias tardes nos boulevares, na Rue de la Paix, no Palais Royal e em alguns ateliês de costura célebres é suficiente para nos ensinar "tudo o que se faz de melhor no mundo", para empregar em seu sentido próprio uma fórmula banal.

Notemos, se quiserem, Senhoras, os raros objetos de pedras e de metais preciosos que podem servir de adornos mais modestos a suas filhas, antes de tratar mais completamente de nosso assunto relativo a uma idade de gozo e de plenitude da vida.

Eis algumas joias que uma mãe elegante poderá escolher para uma jovem de 18 a 20 anos: para um traje casual, brincos de ouro puro chegados à orelha e, combinando com eles, um fecho que passa dentro de uma tira de veludo preto amarrada em torno do pescoço. Outra coisa! Eu procuro nas minhas lembranças do passado, e eu evoco: uma charmosa joia, amarrada sempre ao redor do pescoço, de coral rosa, muito, muito pálido, com um colar parecido; outra de turquesa, com o mesmo fecho (o que cai muito bem a uma jovem), ou ainda de turquesas e pérolas. Eu vejo mesmo, pensando nisso, brincos maiores e um pequeno broche em forma de flechas, com uma pérola fina na extremidade; isso é delicioso!

Todo mundo tem no braço uma pulseira amuleto, de ouro puro ou com pérolas e turquesas; e no dedo um anel, um somente, sempre simples, sem brilhantes ou esmeraldas, esmaltado ou, no máximo, com uma pequena miniatura. No universo da bijuteria, poderemos escolher brincos e uma cruz de prata envelhecida, com pedras de tipo antigo: quer a joia venha da Bretanha, da Provença, da Normandia, da Alemanha ou da Holanda. As joias usadas de dia são completamente diferentes daquelas da noite - nós teriamos um grande cuidado se, por exemplo, tivéssemos que compor uma corbeille de mariage' e dentro colocar umas e outras.

Uma CORBEILLE DE MARIAGE! Começariamos por colocar dentro um par de brincos de ouro, longos (porque a moda assim o quer), com um trabalho absolu- 
tamente artístico, com o qual combinariamos uma linda cruz com corrente; uma segunda joia em lápis-lazúli, pedra muito apreciada hoje em dia; e uma terceira mais elegante: dois cabochons grenás em forma de peras ou maçãs, cujo cabo é decorado com diamantes. Abotoaduras combinando com cada um desses adornos.

Escolheriamos, em seguida, para jantares ou recepções, brincos chegados à orelha e um medalhão cujo centro seria preenchido por uma grande pérola negra, cercada por três fileiras de brilhantes - é um objeto inteiramente novo, nesse momento, nos grandes joalheiros, aqueles cujos nomes foram citados mais acima, ou ainda outros.

Uma belíssima joia poderia ser usada junto com a anterior: composta de safiras talhadas em pequenas placas e cercada de brilhantes. Essa pedra, procurada como nunca hoje, apaga um pouco, mesmo com o seu brilho menos vivo, as maravilhosas esmeraldas. A mesma coisa para o colar. Preferiria essas joias variadas aos eternos solitários de brilhantes, que conhecemos há tanto tempo.

Quem quer conhecer as pulseiras? Ontem vi uma esplêndida de ouro e rubis; depois, vários anéis com brilhantes ou esmeraldas, ou com camafeus (estes últimos estão voltando à moda). Deixo vocês escolherem a presilha para prender o xale.

Um pequeno frasco, em diferentes tipos de ouro - rosa, verde ou amarelo, Luís $\mathrm{XV}$ ou Luís XVI -, com motivos de guirlanda (ou moderno, de esmalte com folhagens e pássaros japoneses), por ser um objeto indispensável ao lado de um lenço de rendas, nós não poderíamos esquecê-lo! E também um leque: de seda preta com guache rosa, azul ou cinza para o traje da manhã, ou de seda branca com pinturas para as cerimônias. 0 sujeito se posiciona de lado e não mais no meio. No entanto, nada valerá mais que um leque, rico, por sua armação, ou mesmo muito simples, mas apresentando, antes de tudo, um valor ideal. Qual? 0 valor de uma pintura: antiga, da Escola de Boucher, de Watteau e talvez feita por esses mestres; moderna, de nosso colaborador Edmond Morin. Cenas de entradas de mansões ou de parques hereditários e do asfalto e da beira do rio, o mundo contemporâneo com sua festa que dura todo o ano: eis o que nos mostram essas raras obras-primas colocadas nas mãos das grandes damas.

Tudo isso exposto por um instante ao olhar de vocês, Senhoras, entra, por vários motivos, na corbeille: um cashmere da Índia por um preço qualquer, essa roupa necessária, mas só usada muito raramente (pois a moda não a admite mais como chique). Que o xale deslize, dos ombros, com seus plissados orientais, e envolva outras maravilhas: todo o delicioso porta-joias que já evocamos aqui, pedra por pedra ou pérola por pérola. Quanto às rendas, nós a queremos por um preço alto, porque essas obras saíram de mãos de fadas, elas mesmas não conhecendo a mediocridade. Babados, ponta, túnica, leque, sombrinha de Chantilly; babados, túnicas, leque, sombrinhas ou lenço: das aplicações de Bruxelas (ponto de agulha), nem precisa escolher! Nós não vamos exagerar nos veludos e na seda em nossa Corbeille, esses tecidos pertencem ao universo da costureira, e a respeito da costureira, ouvi dizer - mas será que se pode prever! - que nós deveríamos esperar por uma mudança radical na tournure ${ }^{2}$. Dizem que não há mais razão para que ela exista, as cinturas não devendo mais ser marcadas já que isto é um fato quase antigo, que elas são usadas longas e mesmo muito longas.

A moda não viria, desta vez, do salão de pintura? Vimos primeiramente, com surpresa, e depois não sem alguma satisfação, um retrato e mesmo vários nos quais jovens e modernos rostos sobressaíam de um desses vestidos de cintura alta dos últimos séculos. Teremos que esclarecer a origem desse ponto curioso no começo de setembro, para ver se essa ressurreição vai permanecer na próxima estação! E também, agora, com os olhos ofuscados por irisações, opalizações, cintilações, poderíamos olhar sobretudo sem dificuldade, algo tão vago quanto o Futuro. 


\section{NOTAS}

${ }^{[1]}$ Antigamente, o futuro esposo oferecia a sua noiva um cesto ou um estojo contendo presentes, especialmente joias.

${ }^{[2]}$ Anágua ampla usada entre 1870 e 1875, cuja parte de trás era proeminente e levantada por uma armadura metálica, para marcar a cintura e colocar em evidência as nádegas e o quadril.

\section{REFERÊNCIAS}

MALLARMÉ, S. La dernière mode: gazette du monde e de la famille. Paris: Editions Ramsey, 1874. Tradução de lzabel Haddad e revisão de Márcia Bandeira. 